\title{
有限要素法による粘弾性流動解析における定式化
}

\author{
岩田修一
}

\section{Finite Element Formulations of Viscoelastic Flow Analysis}

Shuichi IWATA(Materials Science and Engineering, (NAGARE College), Nagoya Institute of Technology, Gokiso-cho, Showa-ku, Nagoya, Aichi, 466-855 Japan)

Flow of viscoelastic fluid such as polymer melt or aqueous solution of polymer is more complex in complex flow geometry even at lower Reynolds number. Rheological behavior of the polymer fluid may change non-linearly as the flow condition. Therefore, flow analysis of such polymer fluid is more important for establishing a reliable design of the processing units. Even though there are useful viscoelastic models available, numerical prediction of viscoelastic fluid is not an easy task, because of hyperbolic nature of the constitutive equation. In the last decades, great progresses have been made on the numerical methods for solving viscoelastic flow problems. In this paper, some of the finite element formulations are described and discussed.

Key Words : Viscoelastic Fluid, Finite Element Method, Formulation, Numerical Analysis

\section{1. は じ め に}

トラブル原因の解明のために，押出成形機内部の樹脂流 動や，射出成形機の金型内部での充てん流れを可視化した いというニーズは大きい. しかしながら，溶融樹脂の流動 の可視化は，高温・高圧という過酷な条件のために，非常 に困難な問題である。一方，流路形状の最適化問題や混練 状況の定量的な評価など，数值解析による設計支援につい ても，同様に大きなニーズがある．経験的な設計手法に対 し，数值解析による結果は設計方針に対して，裏付けを与 えるものとなり得る. 最近, 数值解析結果をわかりやすく 表現するツールが発達し，様々なメディアで紹介されるた め，「シミュレーションをやればすぐに様々な情報が得ら れるだろう」という気にさせられる。そのような背景から， 粘弾性流動解析は，樹脂流動の様々な情報を与えるツール として，大きな期待が寄せられている。そのような期待に 反して，メモリーの使用量は多く，実装置と同じ運転条件 で解析を行うことは容易ではない，そのために，様々な解 析手法の開発が行われてきた。流体モデルの説明は多くの 成書に述べられているが，解析手法に関する説明は余り見 受けない。そこで，今回，有限要素法を中心にその発展の 歴史について簡潔に紹介し，粘弾性流動問題に特有な問題 である定式化手法に焦点をあてることにしたい。その幾つ かを紹介しながら，簡単に解が得られない理由を解説（言
い訳）していきたい。

\section{2. 有限要素法による粘弾性流動問題の各種解法}

\section{1 有限要素法の発達の歴史}

有限要素法は，形状適合性に優れた離散化手法として広 く利用されている。その歴史は古く，1943年にCourant 1,2) がねじり問題を解くために三角形要素の集合と最小化 ポテンシャルエネルギーの原理を使用したのが始まりとさ れ, 工学的な問題には, 航空宇宙工学の分野において, Turner, Clough, Martin, Topp ${ }^{1,3)}$ らの三角形要素を用いた 平面応力問題が最初とされる. Finite Element Method (有限要素法) という言葉は，1960年のClough ${ }^{1,4)} ら の$ 平 面弾性問題の取り扱いを進化させた論文が最初である。こ の後さらに多くの研究がなされ，変分原理を基にしたRitz 有限要素法 $\left.{ }^{1,5}\right)$ が確立した。この有限要素法は，変分の原 理が適用できる弾性連続体問題が中心であり，非線形な問 題には適用出来ない。それとほほ同じ時期に，重み付き残 差法 (Galerkin 法 $)^{1,6)}$ が発展する。要素節点から内挿した

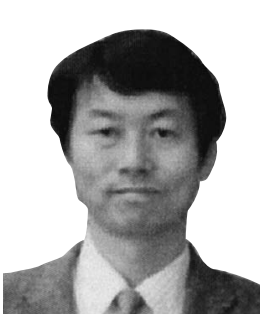

岩田修一; 名古屋工業大学大学院工学研究科物 質工学専攻（４ 466-8555 名古屋市昭和区御器 所町) 助教, 博士 (工学). 平成 3 年, 名古屋工 業大学大学院工学研究科物質工学専攻博士前期 課程修了．専門は，非ニュートン流体力学，化 学工学. 
速度，圧力，応力を用いれば，支配方程式には残差が生じ る. その残差を補間関数（重み関数）によって同様に評価 し, 要素における残差の積分值が 0 を満たす弱解として速 度，圧力，応力節点值が得られる。この方法であれば，支 配方程式と境界条件が与えられれば方程式を組み立てるこ とを意味し，非線形な項を含む流動解析にも適用出来る.

ニュートン流体の流動解析の場合，運動方程式と連続式 が支配方程式となる。たとえば，2次元軸対称問題の場合， 支配方程式を Galerkin 法で定式化・離散化すると, 各要 素節点における速度節点值 $\left(u^{i}, w^{i}\right)$ と圧力節点值 $p^{m}$ という 3 種類の節点值に関する代数方程式系が得られ，ガウス消 去法など適当な連立一次方程式用ソルバー等で解かれる.

しかしながら, 粘弾性流体の流動解析の場合は, 支配方 程式に，物質のレオロジー特性（弾性応力と変形速度の関 係）を示す構成方程式が新たに加わる，すなわち，ある要 素の 1 節点に着目すると，速度・圧力に関する 3 種類の節 点值だけでなく，応力に関する 4 種類の節点值が追加され るため, 自由度は著しく増加し, 離散化マトリックスのサ イズも非常に大きくなる。

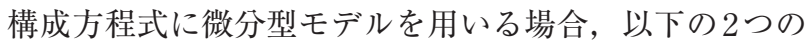
取扱法が可能である.1つめは, 運動方程式, 連続式, 構 成方程式すべてを同時に解く混合法（Mixed method）で あり，2つめは，連続式・運動方程式と構成方程式との 2 グループに分割し，それぞれのグループを別々に交互に解 く分割法 (Decoupled method) である.

混合法は，すべての支配方程式を同時に解くため大規模 メモリーを要するという短所があるものの収束性（計算安 定性）に優れている。この短所は，近年，64ビット演算 CPUが容易に入手できることやOpen MPをはじめとする 並列計算基盤技術の普及により，この制約は緩やかになっ た。しかしながら，3次元解析では，依然としてメモリー 使用量がネックとなることは避けられない。混合法に関す る多くの研究報告がなされており，その概要を後述する.

一方，分割法は，支配方程式を 2 グループに分割して解 くためマトリックスサイズが縮小し，低メモリーで計算が 行えるという長所を有する。しかしながら，速度場・圧力 場を解く場合には，本来は未知である応力を既知として扱 い，応力場を解く場合には，本来は未知である速度場を既 知として扱い，反復計算により収束解を求めるため，混合 法に比べて収束性は極めて悪いことが知られている（Mitsoulis $^{7)}$, Luo and Tanner ${ }^{8)}$, Iwata et al. ${ }^{9)}$ ).

\section{2 混合法}

速度場，圧力場，応力場をすべて未知として同時に解く 混合法を用いた有限要素法解析は, Kawahara and Takeuchi $^{10)}$ によって初めて報告された。 その後，定式化 の検討や各変数に対する近似関数（多項式）の次数の検討
が行われた。その中で, 応力の代入方法と近似関数の次数 の組合せに関する検討については, Crochet and Keunings ${ }^{11)}$ やV Van Schaftingen and Crochet ${ }^{12)}$ の報告がある. 後者では，UCM モデル（Upper Convected Maxwell model）を用いて以下に示す MIX1〜MIX4 という 4 種類 の定式化が提案された。 以下に，各定式化について概説す る.

$\diamond$ MIX 法

支配方程式は，次の運動方程式，連続式，構成方程式 (UCMモデル*) である.

$$
\begin{aligned}
& \rho \boldsymbol{a}=-\nabla p+\nabla \cdot \boldsymbol{\tau}+\rho \boldsymbol{g} \\
& \nabla \cdot \boldsymbol{v}=0 \\
& \boldsymbol{\tau}+\lambda \stackrel{\nabla}{\boldsymbol{\tau}}=2 \eta \boldsymbol{S}
\end{aligned}
$$

ここに， $\rho$ は密度， $\eta$ は粘度，vは速度べクトル， $a$ は 加速度ベクトル， $\tau$ は偏差応力テンソル,$g$ は重力加速度 ベクトル， $\lambda$ は緩和時間であり, $\boldsymbol{S} \equiv\left(\nabla \boldsymbol{v}+\nabla \boldsymbol{v}^{\mathrm{T}}\right) / 2$ は変形 速度テンソルである. 全応力テンソル $\boldsymbol{T}$, 等方性の圧力, 偏差応力テンソル $\boldsymbol{\tau}$ は, $\boldsymbol{T}=-p \boldsymbol{\delta}+\boldsymbol{\tau}$ で関係づけられる. また，（1）〜（3）式を成分式で表すと複雑になるため， 太字で示すべクトルやテンソルを用いて表記した。構成方 程式（3）中の上付記号 ' $\nabla$ ' は, 反変型対流時間微分で あり,流体とともに移動・変形・回転する座標系に対して, 物質客観性の原理を満足する特殊な時間微分である.

Crochet らは，運動方程式 (1), 連続式 (2), 構成方程 式（3）にそれぞれ重み関数 $\left(\phi^{i}, \psi^{j}, \varphi^{k}\right)$ を掛け, Galerkin 法により定式化し，次式のMIX1を与えた。ただし，内積 記号（**脚注参照）を用いて表記されていることに注意 されたい.

《MIX1》

$$
\left\{\begin{array}{l}
\left\langle\left(\nabla \phi^{i}\right)^{\mathrm{T}} ;-p \boldsymbol{\delta}+\boldsymbol{\tau}\right\rangle+\left\langle\phi^{i} ; \rho \boldsymbol{a}\right\rangle=\boldsymbol{F}^{i} \\
\left\langle\psi^{j} ; \nabla \cdot \boldsymbol{v}\right\rangle=0 \\
\left\langle\varphi^{k} ; \boldsymbol{\tau}+\lambda \stackrel{\nabla}{\boldsymbol{\tau}}-2 \eta \boldsymbol{S}\right\rangle=0
\end{array}\right.
$$

【近似関数】 $\Rightarrow\left(\right.$ 速度 $\mathrm{P}^{2}-\mathrm{C}^{0}$, 圧力 $\mathrm{P}^{1}-\mathrm{C}^{0}$, 応力 $\left.\mathrm{P}^{2}-\mathrm{C}^{0}\right)$ ここに， $\delta$ は単位テンソルである。近似関数（多項式） の特性を示す表記法 ' $\mathrm{P}^{m}-\mathrm{C}^{n}$ ' は, 近似関数が $m$ 次多項式 からなり，要素間で $n$ 階微分までが連続性を有することを

\footnotetext{
*UCM（Upper Convected Maxwell model）流体は，ダッシュポッ 卜要素とスプリング要素が直列に結合されたモデルで表現される粘 弾性流体である。ダッシュポットの滑りは粘性流動を, スプリング の伸びは弾性変形を表す．物理的にUCM 流体は，せん断粘度が一定 值を示しつつ（Shear thinning 性を示さず）法線応力差が発生する 流体である。現実流体としてBoger 流体がUCM 流体の挙動を示す. せん断速度 $\rightarrow$ 無限大にすると, 法線応力差 $\rightarrow$ 無限大となる性質があ る. 詳細は, 成書 $\left(\right.$ Nakamura $\left.{ }^{13)}\right)$ 拈よび参考文献 (Tam and $\mathrm{Tiu}^{14)}$ ) を参照されたい。

** $\langle f ; g\rangle \equiv \int_{D} f g d D ; D$ は, 着目する要素の領域を意味する.
} 
意味する.（4）式中の右辺 $\boldsymbol{F}^{i}$ は体積力と面積力の寄与を 示す.

このMIX1による定式化では，運動方程式（4）中に2 次微分項 $\nabla^{2} \boldsymbol{v}$ が存在しない。したがって， $\lambda=0$ の極限の 場合に対応するニュートン流体の定式化とは一致しないと いう久点を有する。また，運動方程式は楕円型でなく，数 值安定性に問題があることがわかる.

そこで, 構成方程式（3）を $\tau=2 \eta S-\lambda \boldsymbol{\tau}^{\nabla}$ と変形し, 運 動方程式に代入後, 変形すると, 次式の MIX2を得る。た だし，この場合，応力に $\left(\mathrm{P}^{2}-\mathrm{C}^{0}\right)$ 級の近似関数を用い る.

《MIX2》

$$
\left\{\begin{array}{l}
\left\langle\left(\nabla \phi^{i}\right)^{\mathrm{T}} ;-p \boldsymbol{\delta}+\eta\left(\nabla \boldsymbol{v}+\nabla \boldsymbol{v}^{\mathrm{T}}\right)-\lambda \boldsymbol{\tau}\right\rangle+\left\langle\phi^{i} ; \rho \boldsymbol{a}\right\rangle=\boldsymbol{F}^{i} \\
\left\langle\psi^{j} ; \nabla \cdot \boldsymbol{v}\right\rangle=0 \\
\left\langle\varphi^{k} ; \boldsymbol{\tau}+\lambda \underset{\boldsymbol{\tau}}{\nabla}-2 \eta \boldsymbol{S}\right\rangle=0
\end{array}\right.
$$

【近似関数】 $\Rightarrow$ (速度 $\mathrm{P}^{2}-\mathrm{C}^{0}$, 圧力 $\mathrm{P}^{1}-\mathrm{C}^{0}$, 応力 $\left.\mathrm{P}^{2}-\mathrm{C}^{0}\right)$

また，MIX2の定式化をそのまま用い，応力の近似関数 のみを $\left(\mathrm{P}^{1}-\mathrm{C}^{0}\right)$ 級に変更すると, MIX3の方法が得られ る.

《MIX3》

MIX2 と同じ定式化

【近似関数】 $\Rightarrow\left(\right.$ 速度 $\mathrm{P}^{2}-\mathrm{C}^{0}$, 圧力 $\mathrm{P}^{1}-\mathrm{C}^{0}$, 応力 $\left.\mathrm{P}^{1}-\mathrm{C}^{0}\right)$

また, MIX4では, さらに, 構成方程式中の偏差応力 $\tau$ を, 粘性寄与項 $2 \eta \boldsymbol{S}$ と弾性寄与項 $\boldsymbol{E}$ に分解する.

$$
\left\{\begin{array}{l}
\boldsymbol{\tau}=2 \eta \boldsymbol{S}+\boldsymbol{E} \\
\boldsymbol{E}+\lambda \stackrel{\nabla}{\boldsymbol{E}}+2 \lambda \eta \stackrel{\nabla}{\boldsymbol{S}}=0
\end{array}\right.
$$

したがって，MIX4の方法は，以下の如く与えられる。 《MIX4》

$$
\left\{\begin{array}{l}
\left\langle\left(\nabla \phi^{i}\right)^{\mathrm{T}} ;-p \boldsymbol{\delta}+\eta\left(\nabla \boldsymbol{v}+\nabla \boldsymbol{v}^{\mathrm{T}}\right)-\lambda \boldsymbol{\nabla}\right\rangle+\left\langle\phi^{i} ; \rho \boldsymbol{a}\right\rangle=\boldsymbol{F}^{i} \\
\left\langle\psi^{j} ; \nabla \cdot \boldsymbol{v}\right\rangle=0 \\
\left\langle\varphi^{k} ; \boldsymbol{\tau}-2 \eta \boldsymbol{S}+\boldsymbol{E}\right\rangle=0 \\
\left\langle\varphi^{k} ; \boldsymbol{E}+\lambda \stackrel{\nabla}{\boldsymbol{E}}+2 \lambda \eta \stackrel{\nabla}{\boldsymbol{S}}\right\rangle=0
\end{array}\right.
$$

【近似関数】 $\Rightarrow\left(\right.$ 速度 $\mathrm{P}^{2}-\mathrm{C}^{0}$, 圧力 $\mathrm{P}^{1}-\mathrm{C}^{0}$, 応力 $\left.\mathrm{P}^{1}-\mathrm{C}^{0}\right)$ ただし，（11）式の対流時間微分 $\stackrel{\sim}{S}$ 中に速度の 2 階微分 を含むので，部分積分とガウスの発散定理とを用いて微分 の階数を減らす必要がある。

これら MIX3，MIX4を用いた解析では，速度の 2 階微 分項 $\nabla^{2} \boldsymbol{v}$ が生じるため，MIX1の欠点が克服されている.

MIX2を用いた解析では，MIX3の場合と異なり，応力 場に $\left(\mathrm{P}^{2}-\mathrm{C}^{0}\right)$ 級の近似関数を用いるが，収束解に数值
振動が顕著に現れ，収束性も劣悪であることが報告されて いる.

その後, Marchal and Crochet ${ }^{15)}$ は, 応力場の離散化に 対し, サブエレメント法，すなわち，要素をさらに $2 \times 2$, $3 \times 3,4 \times 4$ に分割する方法を導入した。 その結果， MIX4をベースに，流線上流法（SU 法）と $4 \times 4$ サブエレ メント法を用いて Oldroyd-B流体の流動解析を行い，収束 性の大幅な改善が得られたと報告している。

このように，同一の支配方程式から出発して定式化を行 ったにもかかわらず，その定式化の仕方によって収束性や 収束結果が異なることが示された。商用ソフトには，要素 (近似関数）の選択が可能なものがあるが，その選択によ って, 収束性や計算結果が異なることを示唆しており, 解 析結果の妥当性を見極めることが重要である.

\section{$\diamond$ 付加粘性}

Luo and Tanner ${ }^{16)}$ は，非等温非圧縮性の粘性流体を対 象とする有限要素プログラムNACHOSESに流線要素法 （Streamline element scheme）を導入し，粘弾性流体版に 拡張した。彼らは，定式化の過程で，次式に示す参照粘性 （Reference viscous stress）項性 $2 \eta_{r} S$ を導入した。

$$
\begin{aligned}
& \boldsymbol{\sigma}=-p \boldsymbol{\delta}+2 \eta_{r} \boldsymbol{S}+\boldsymbol{\tau} * \\
& \boldsymbol{\tau}^{*}=\boldsymbol{\tau}+2\left(\eta_{s}-\eta_{r}\right) \boldsymbol{S}
\end{aligned}
$$$$
\text { ここに, } \sigma \text { は全尤力テンツル (Cauthy stress }
$$
到はニュートン粘性である。 Luo and Tannerは， $\eta_{r}$ を参 照粘性（reference viscosity）と名付けた。 上式中の $\tau^{*}$ は, 応力を運動方程式に代入したとき，擬似体積力として扱わ れる．参照粘性 $\eta_{r}$ にある数值（正值）を設定すると，全 応力 $\sigma$ 中の粘性応力寄与が増大し, 定式化・離散化の結果 得られるマトリックス方程式の優対角化が実現され, 数值 安定性が改善される。

Tanoue et al. ${ }^{17)}$ は，付加粘性の概念を用いた TME (Transformation of Momentum equation to the Elliptic equation）を提案し，Giesekus モデル流体を対象した 2 重 管ダイスウェル流動問題を混合法で解析を行った.

慣性項・重力項を無視したStokes 流れの運動方程式 （14）に，（8）式を代入すると，（15）式の如く変形できる.

$$
\begin{aligned}
& -\nabla p+\nabla \cdot \boldsymbol{\tau}=0 \\
& -\nabla p+\nabla \cdot \boldsymbol{E}+2 \eta \nabla \cdot \boldsymbol{S}=0
\end{aligned}
$$

運動方程式 (15) の両辺に付加粘性項 $2 \eta f \nabla \cdot S$ を加えると, 次式が得られる。

$$
-\nabla p^{(n+1)}+\nabla \cdot \boldsymbol{E}^{(n+1)}+2 \eta(1+f) \nabla \cdot \boldsymbol{S}^{(n+1)}=2 \eta f \nabla \cdot \boldsymbol{S}^{(n)}
$$

ここに，上付指標 $(n+1)$ は，反復 $(n+1)$ 段目の計算 における未知変数を意味し, 上付指標 $(n)$ は, 反復前段 （ $n$ 段）で得られた近似解を用い，既知関数として扱うこ とを意味する，収束時には，左辺の $2 \eta f \nabla \cdot \boldsymbol{S}^{(n+1)}$ と右辺 の $2 \eta f \nabla \cdot S^{(n)}$ が一致し，付加粘性項の影響は消滅する. 
運動方程式（16）中の $\eta f$ は付加粘性の意味を持ち，パ ラメータ $f$ を適当に規定すると, 付加粘性項の寄与により 運動方程式は楕円型に保持される. Tanoue et al.は，この 付加粘性の概念を用いることにより，ワイゼンベルグ数 (We ) が 450 という高ワイゼンベルグ数領域にて収束解を 得ることに成功した。ここに，ワイゼンベルグ数とは，緩 和時間 $\lambda$, 代表速度 $U$, 代表長さ $L$ を用いて, $W e \equiv \lambda U / L$ により定義される無次元数であり, 弾性力と粘性力との比 を表す指標として用いられる ${ }^{18)}$.

Tanoue et al.は, 計算領域すべてに一定の付加粘性を適 用したが，Baaijens et al. ${ }^{19)}$ やOtsuki et al. ${ }^{20)}$ は，付加粘 性を状態量の関数として設定する手法を提案した。

$\diamond$ EVSS 法

一般に有限要素法では, 要素上の值を, 着目要素の節点 值から Lagrange 補間公式により内挿するという Lagrange 要素が多用されているが，この場合，要素境界上にて速度 微分值に連続性が保たれないという久点がある.すなわち, 同一節点を共有する要素間で，どの要素に着目するかによ って，速度微分值が異なった值を示す。速度微分值は，構 成方程式中の複数項に現れ，これを精度良く評価すること が収束性に顕著に影響する。

この速度微分值の評価法改善に関連する手法として, Rajagopalan et al. ${ }^{21)}$ は, 偏差応力を粘性応力と弾性応力 とに分離し, 速度 - 圧力 - 応力に加えて変形速度テンソル を新たな未知数と見なして定式化する EVSS 法（ElasticViscous Split Stress）を提案した．使用する計算メモリー 量は若干増えるが，収束性が著しく改善されることが報告 されている，以下にEVSS法を概説する。

EVSS法では，（20）式に示す偏差応力 $\boldsymbol{\tau}$ を粘性応力 $\boldsymbol{\tau}_{v}$ と弾性応力 $\tau_{e}$ に分離する.

$$
\begin{aligned}
& \boldsymbol{\tau}=\boldsymbol{\tau}_{v}+\boldsymbol{\tau}_{\boldsymbol{e}} \\
& \boldsymbol{\tau}_{v}=\eta_{a}^{*}\left(\nabla \boldsymbol{v}+\nabla \boldsymbol{v}^{\mathrm{T}}\right)
\end{aligned}
$$

ここに, $\eta_{a}{ }^{*}$ は零せん断粘度に対するポリマー寄与の粘 度である。

（17），(18）式を Stokes 流れに関する運動方程式（14） と構成方程式（3）に代入すると，それぞれ（19），(20） 式が得られる。この両式と連続式および変形速度テンソル $S$ に関する方程式（21）を加え，支配方程式系を形成する. この EVSS 法の特徴は, 変形速度テンソル $S$ を未知数とし て扱う所にある。

$$
\begin{aligned}
& \nabla \cdot\left[\eta_{a}^{*}\left(\nabla \boldsymbol{v}+\nabla \boldsymbol{v}^{\mathrm{T}}\right)\right]-\nabla p+\nabla \cdot \boldsymbol{\tau}_{\boldsymbol{e}}=0 \\
& \boldsymbol{\tau}_{\boldsymbol{e}}+2\left(\eta_{a}^{*}-\eta\right) \boldsymbol{S}+\lambda \stackrel{\nabla}{\boldsymbol{\tau}_{\boldsymbol{e}}+2 \lambda \eta_{a}^{*} \stackrel{\nabla}{\boldsymbol{S}}=0} \\
& \nabla \cdot \boldsymbol{v}=0
\end{aligned}
$$

$$
\boldsymbol{S}-\left(\nabla \boldsymbol{v}+\nabla \boldsymbol{v}^{\mathrm{T}}\right) / 2=0
$$

この場合, 変形速度テンソル $\boldsymbol{S}$ は独立に節点未知数とし て求められ, 要素間における連続性が確保されるため, 収 束性が大幅に向上する. 中程度のDeborah数 (De) では, 数值安定性と精度は大幅に改善されるが，あるDe以上で は，メッシュの細粗にかかわらず計算不能となる。ここに， Deは，流体の見かけの緩和時間と流れの変化を示す代表 時間との比で表される無次元数であり, Deが大きい場合, 流体の弾性的応答が強いことを示している ${ }^{18)}$.

EVSS 法の概念は多くの研究者により拡張された。 Brown et $a l^{22)}$ やSzady et al. ${ }^{23)}$ は速度勾配テンソル $\nabla v$ に 注目し，その連続性を保持するように定式化する EVSS-G 法を提案した。すなわち, 次式

$$
\boldsymbol{G} \equiv \nabla \boldsymbol{v}
$$

の如くテンソル $\boldsymbol{G}$ を導入し，このテンソル $\boldsymbol{G}$ を節点未知数 として求め, 構成方程式の求解を数值的に安定化させる方 法である。

Liu et $a l^{24)}$ は, 前述の EVSS-G法に次の概念を導入した. すなわち，運動方程式に粘性項を加算・減算し，その一方 を未知，他方を既知として取扱うことにより，数值安定性 を改善する手法を併用した。この解法はDiscrete splitting method（DEVSS-G法）と呼ばれ，EVSS-G 法と同じ精 度・安定性を有する。

Giesekus 流体の流動解析にDEVSS-G 法を適用したSun et $a$. $^{25)}$ の研究を以下に述べる。この場合, Giesekus 流体 の構成方程式は, 偏差応力 $\boldsymbol{\tau}$ を solvent寄与 $\boldsymbol{\tau}_{s}$ と polymer 寄与 $\boldsymbol{E}$ とに分離して次式の如く与えられる.

$$
\begin{gathered}
\boldsymbol{\tau} \equiv \boldsymbol{\tau}_{\boldsymbol{s}}+\boldsymbol{E}=\eta_{0} s\left(\nabla \boldsymbol{v}+\nabla \boldsymbol{v}^{\mathrm{T}}\right)+\boldsymbol{E} \\
\boldsymbol{E}+\lambda \stackrel{\nabla}{\boldsymbol{E}}+\frac{\alpha}{\boldsymbol{G}} \boldsymbol{E} \cdot \boldsymbol{E}=\eta_{0}(1-s)\left(\nabla \boldsymbol{v}+\nabla \boldsymbol{v}^{\mathrm{T}}\right) \\
\stackrel{\nabla}{\boldsymbol{E}} \equiv \frac{\partial \boldsymbol{E}}{\partial t}+\boldsymbol{v} \cdot \nabla \boldsymbol{E}-\nabla \boldsymbol{v}^{\mathrm{T}} \cdot \boldsymbol{E}-\boldsymbol{E} \cdot \nabla \boldsymbol{v}
\end{gathered}
$$

Stokes 流れを対象とした場合，運動方程式（14）と （22），(23）式より次式が得られる.

$$
\begin{aligned}
& \eta_{0} s \nabla \cdot\left(\boldsymbol{G}+\boldsymbol{G}^{\mathrm{T}}\right)-\nabla p+\nabla \cdot \boldsymbol{E}=0 \\
& \text { この式の左辺に } \boldsymbol{\nabla} \cdot\left[\eta_{a}^{*}\left(\boldsymbol{\nabla} \boldsymbol{v}+\boldsymbol{\nabla} \boldsymbol{v}^{\mathrm{T}}\right)\right]-\boldsymbol{\nabla} \cdot\left[\eta_{a}^{*}\left(\boldsymbol{G}+\boldsymbol{G}^{\mathrm{T}}\right)\right] \text { を加 }
\end{aligned}
$$
算し，整理すると（27）式が得られ，DEVSS-G法におけ る運動方程式が完成する。

$$
\boldsymbol{\nabla} \cdot\left[\eta_{a}^{*}\left(\boldsymbol{\nabla} \boldsymbol{v}+\boldsymbol{\nabla} \boldsymbol{v}^{\mathrm{T}}\right)\right]-\boldsymbol{\nabla} p+\boldsymbol{\nabla} \cdot \boldsymbol{E}-\boldsymbol{\nabla} \cdot\left[\left(\eta_{a}^{*}-\eta_{0} s\right)\left(\boldsymbol{G}+\boldsymbol{G}^{\mathrm{T}}\right)\right]=0
$$

ここで，定式化の途中の運動方程式（26）式に注目しよ j。運動方程式は，本来，未知の速度場 $v$ に関する微分方 
程式である，ところが，後段で説明する分割法を用いる場 合， $\boldsymbol{G}$ は（22）式より得られる既知のテンソルであり, （26）式では，速度の 2 階微分項（最高次の微分項）がこ の既知関数 $\boldsymbol{G}$ の微分に置き換えられている.すなわち, （27）式はもはや未知の速度場 $\boldsymbol{v}$ を規定する運動方程式で はなくなっており，この式を経由する定式化には疑問が残 る。

EVSS法による最近の報告では, Sunwoo et $a l .{ }^{26)}$ が, UCM とPTT モデル流体（Phan-Tien-Tanner モデル流 体 ; 高分子のネットワーク理論に基づいたものであり，非 線形応力を与える ${ }^{27)}$ ) を用いて，3次元流動解析を行った 例がある．また，市販の流動解析ソフトウェアでは，オプ ションとしてEVSS 法とDEVSS 法の定式化を利用するこ とが出来る(例えばPolyflow Users Guide ${ }^{28)}$ ).

以上，EVSS法の概略を述べてきたが，EVSS法は収束 性が良い反面，解くべき支配方程式が増えるため，大規模 メモリーを要するという欠点がある。

今回略述した混合法に基づく種々の解法は，何れの場合 も大規模メモリーを要するという重大な欠点があり，複雑 系・ 3 次元系への適用には問題が残る.

\section{3 分割法}

運動方程式・連続式と構成方程式とを別々に交互に解く 分割法は，低メモリー型の長所を有するが，収束可能最大 Weが高々 1 のオーダーと極めて低い值であり，計算収束 性が劣るため研究報告例は少ない7,8).

Tseng and $\operatorname{Lin}^{29)}$ は，多モードLeonovモデルの平板テ ーパー縮小流れ問題を分割法を用いて解いた。彼らは, artificial viscosity ${ }^{30)}$ と称される特殊な粘性項を導入し, 次の如く運動方程式を修正することにより, De = 27.5 ま での収束解を得た。

すなわち, Stokes 流れの運動方程式（14）について， その両辺に 2 次微分項 $\eta_{a}^{+} \nabla^{2} v$ を加えて, 次式

$$
\left(\eta+\eta_{a}^{+}\right) \nabla^{2} \boldsymbol{v}-\nabla p+\nabla \cdot \hat{\boldsymbol{\tau}}=\eta_{a}^{+} \nabla^{2} \hat{\boldsymbol{v}}
$$

の如く変形し, 左辺の付加項 $\eta_{a}^{+} \nabla^{2} \boldsymbol{v}$ を未知, 右辺の付加 項 $\eta_{a}^{+} \nabla^{2} \hat{v}$ を既知として取扱う方法を用いた。ここに，上付 記号 ‘^’ は，反復前段の近似解を用いて既知として取扱 うことを意味する。 $\hat{v}$ は反復前段の速度場（近似解）であ り， $\hat{\tau}$ は反復前段の構成方程式から得られた応力場（近似 解）である.これらの既知項は擬似体積力として扱われる. なお，収束時には，vと $\hat{v} ， \boldsymbol{\tau}$ と $\hat{\tau}$ はそれぞれ一致する.

Schmidt et $a l^{31)}$ は，ペナルティ法により支配方程式系 から連続式を除去し,ブロー成形の非定常流動解析を行い, 低 $D e$ 領域にて推定值と実測值とが良好に一致することを 報告した。

\section{$\diamond$ AVSS法}

分割型有限要素法の低メモリー型解法という長所に注目
して，その収束性改善のための検討がなされている.Sun et $a l^{32)}$ は, AVSS (Adaptive Viscoelastic Stress Splitting）法を提案し，その収束性の改善効果を確認した.

AVSS法では，任意の着目要素について，要素代表寸法 $h_{e}$ と各変数の最大值 $\left(|\boldsymbol{v}|_{\max },|p|_{\max },|\boldsymbol{\tau}|_{\max }\right)$ を用い 各変数を次式の如く正規化する。

$$
\begin{array}{rlrl}
\bar{x} & \equiv \frac{x}{h_{e}} & (29), & \overline{\boldsymbol{v}} \equiv \frac{\boldsymbol{v}}{|\boldsymbol{v}|_{\max }} \\
\bar{p} \equiv \frac{p}{|p|_{\max }} & (31), & \overline{\boldsymbol{\tau}} \equiv \frac{\boldsymbol{\tau}}{|\boldsymbol{\tau}|_{\max }}
\end{array}
$$

これらの定義をEVSS法で定式化した運動方程式（19) に代入し， $\eta_{a}{ }^{*}$ を $\eta_{a d p}$ と書き換えると次式を得る.

$$
\left[\frac{|\boldsymbol{v}|_{\max }}{\left|\boldsymbol{\tau}_{\boldsymbol{e}}\right|_{\max } h_{e}} \eta_{a d p}\right] \bar{\nabla}^{2} \overline{\boldsymbol{v}}-\frac{|p|_{\max }}{\left|\boldsymbol{\tau}_{\boldsymbol{e}}\right|_{\max }} \bar{\nabla} \bar{p}+\bar{\nabla} \cdot \overline{\boldsymbol{\tau}}_{\boldsymbol{e}}=0
$$

応力が極めて大きい場合でも，（33）式左辺第 1 項の係 数は常に1オーダーの值となるように， $\eta_{\text {adp }}$ を次の如く与 える。

$$
\eta_{a d p}=\alpha \frac{\left|\boldsymbol{\tau}_{\boldsymbol{e}}\right|_{\max } h_{e}}{|\boldsymbol{v}|_{\max }}
$$

この工夫により運動方程式は常に楕円型となる。 $\eta_{\text {adp }}$ は 適合粘性（adaptive viscosity）と呼ばれ，上式中の $\alpha$ は 1 オーダーの定数である.

このように，要素毎に異なる適合粘性（ $\left.\eta_{\text {adp }}\right)$ を運動方 程式（19）式に適用する解法をAVSS 法という.

Sun et $a l^{32)}$ は，このAVSS 法を用いてUCM流体の円管 Poiseuille 流れ（乱れのない円管流れ）を解析し，収束可 能最大 $W e$ には上限がなく,$W e=10^{4}$ にて計算を停止した と述べている。また，円管内に設置した球まわりの流れ解 析について，AVSS 法と流線積分法（SI）を併用する $\mathrm{AVSS} / \mathrm{SI}$ 法により，We = 3.2 まで収束解を得た。流線上 流法（SUPG）を併用するAVSS/SUPG 法によると， $W e=1.55$ であった。一方，AVSS法を適用せず，分割法 のみで計算すると, $W e=0.3$ という極めて低い值までしか 収束解が得られなかったと報告している。

AVSS法は，ある着目点における適合粘性がその点での 速度・応力の関数形で与えられるため, 実際に解く離散化 式はもとの基礎式と完全には一致しないという問題点があ る。

$\diamond$ 応力代入法と特性テンソル

分割型有限要素法の低メモリー型解法という長所に注目 して，その収束性改善のための検討がなされている。 Iwata et al. ${ }^{9)}$ は，運動方程式を解く際に，運動方程式へ の応力代入法により，その収束性が異なることを示した。 粘弾性流体の構成方程式には, 次式の単一モード 
Giesekusモデルが用いられた。

$$
\begin{aligned}
& \boldsymbol{\tau}=2 \eta_{0} s \boldsymbol{S}+\boldsymbol{E} \\
& \boldsymbol{E}+\lambda \stackrel{\nabla}{\boldsymbol{E}}+\frac{\alpha}{\boldsymbol{G}} \boldsymbol{E}^{2}=2 \eta_{0}(1-s) \boldsymbol{S}
\end{aligned}
$$

ここに, $\boldsymbol{S} \equiv\left[\nabla \boldsymbol{v}+\nabla \boldsymbol{v}^{\mathrm{T}}\right] / 2$ は変形速度テンソル， $\eta_{0}$ は零 せん断粘度， $\lambda$ は緩和時間， $\alpha$ および $s$ はデルパラメー 夕 $(0 \leqq \alpha \leqq 1,0 \leqq s \leqq 1), G \equiv \eta_{0}(1-\mathrm{s}) / \lambda$ は緩和弾性 率である。 $\stackrel{\nabla}{\boldsymbol{E}}$ は反変型対流時間微分であり，定常状態では 次式で定義される。

$$
\stackrel{\nabla}{\boldsymbol{E}} \equiv \boldsymbol{v} \cdot \nabla \boldsymbol{E}-\left(\nabla \boldsymbol{v}^{\mathrm{T}} \cdot \boldsymbol{E}+\boldsymbol{E} \cdot \nabla \boldsymbol{v}\right)
$$

定常流れの運動方程式は次式の通りである.

$\rho \boldsymbol{v} \cdot \nabla \boldsymbol{v}=-\nabla p+\nabla \cdot \boldsymbol{\tau}+\rho \boldsymbol{g}$

運動方程式（38）式に応力を代入する際，次の $2 つ の$ 方 法が可能である。すなわち，（35）式を直接代入する「直 接代入法」と，（36），（37）式を用いて（35）式を変形後 に（38）式へ代入する「変形代入法」である．運動方程式 に代入される応力はそれぞれ次式のようになる。

[直接代入法]

$$
\begin{aligned}
& \tau=\nabla \boldsymbol{v}^{\mathrm{T}} \cdot \chi_{D}+\chi_{D} \cdot \nabla \boldsymbol{v}+\hat{\boldsymbol{E}} \\
& \chi_{D} \equiv \eta_{0} s \boldsymbol{\delta}
\end{aligned}
$$

[変形代入法]

$$
\begin{aligned}
& \boldsymbol{\tau}=\nabla \boldsymbol{v}^{\mathrm{T}} \cdot \chi_{R}+\chi_{R} \cdot \nabla \boldsymbol{v}-\lambda \boldsymbol{v} \cdot \nabla \hat{\boldsymbol{E}}-\frac{\alpha}{\boldsymbol{G}} \hat{\boldsymbol{E}}^{2} \\
& \chi_{R} \equiv \eta_{0} \delta+\lambda \hat{\boldsymbol{E}}
\end{aligned}
$$

ここで，上付記号“へ”は，反復計算の前段で得られた 近似解を用いて，既知関数と見なすことを意味する。 $\chi_{D}$ と $\chi_{R}$ は ‘特性テンソル’であり， $\eta_{0}$ を大きくすると粘性 力が増加し，計算安定性が増す性質を持つ。 $\chi_{D}$ と $\chi_{R}$ とを 比較すると， $\chi_{D}$ には 1 より小なモデルパラメータ $s$ を含 むが， $\chi_{R}$ にはsはなく，より大きな值になる，また新たな 寄与項 $\lambda \hat{\boldsymbol{E}}$ が付加されている. Iwata et al. ${ }^{9)}$ は，通常要素 を用いたダイスウェル流動問題で検討し，特性テンソルの 違いにより，変形代入法の方が直接代入法よりも良い収束 性が得られたと報告した。また，分割法に特有に生じる補 間法や積分問題に注目し，収束性を大幅に改善することに 成功している Iwata et al. ${ }^{9,33,34)}$.

さらに, Iwata et al. ${ }^{35)}$ は, Tanoue et al. ${ }^{17)}$ の付加粘性 の概念を参考に，(41）式右辺に $2 \eta_{a} \boldsymbol{S}-2 \eta_{a} \hat{\boldsymbol{S}}$ を加える方法 を提案した。

$$
\boldsymbol{\tau}=\nabla \boldsymbol{v}^{\mathrm{T}} \cdot \chi_{R}+\chi_{R} \cdot \nabla \boldsymbol{v}-\lambda \hat{\boldsymbol{v}} \cdot \nabla \hat{\boldsymbol{E}}-\frac{\alpha}{\boldsymbol{G}} \hat{\boldsymbol{E}}^{2}+\left(2 \eta_{a} \boldsymbol{S}-2 \eta_{a} \hat{\boldsymbol{S}}\right)
$$

$2 \eta_{a} \hat{\boldsymbol{S}}$ は反復前段の解で評価した変形速度テンソルの既 知関数である. なお, この項は, 式中の他の既知関数項と ともに運動方程式中で重力と同じように領域全体に作用す る擬似体積力（pseudo-body force）として取り扱われる. 反復計算の収束時には $2 \eta_{a} \boldsymbol{S}$ と $2 \eta_{a} \hat{\boldsymbol{S}}$ の両者は一致し，運動 方程式に代入する式は元の（41）式に帰着する。ここで, 特性テンソル $\chi_{R a}$ を用いて（43）式を整理すると，

$$
\begin{aligned}
\boldsymbol{\tau}= & \nabla \boldsymbol{v}^{\mathrm{T}} \cdot \chi_{R a}+\chi_{R a} \cdot \nabla \boldsymbol{v}-\lambda \hat{\boldsymbol{v}} \cdot \nabla \hat{\boldsymbol{E}}-\frac{\alpha}{\boldsymbol{G}} \hat{\boldsymbol{E}}^{2}-\eta_{a}\left(\nabla \hat{\boldsymbol{v}}+\nabla \hat{\boldsymbol{v}}^{\mathrm{T}}\right) \\
& \chi_{R a} \equiv\left(\eta_{0}+\eta_{a}\right) \boldsymbol{\delta}+\lambda \hat{\boldsymbol{E}}
\end{aligned}
$$

となる。（42）式と（45）式を比較すると，特性テンソル $\chi_{R a}$ は付加粘性量 $\eta_{a} \delta$ だけ対角項の増加がみられる.

(44) 式中の擬似体積力に相当する項をテンソル量 $\boldsymbol{c}$ と してまとめて整理すると，次式が得られる。

$$
\begin{aligned}
\boldsymbol{\tau} & =\nabla \boldsymbol{v}^{\mathrm{T}} \cdot \chi_{R a}+\chi_{R a} \cdot \nabla \boldsymbol{v}-\boldsymbol{c} \\
\boldsymbol{c} & \equiv \lambda \hat{\boldsymbol{v}} \cdot \nabla \hat{\boldsymbol{E}}+\frac{\alpha}{\boldsymbol{G}} \hat{\boldsymbol{E}}^{2}+\eta_{a}\left(\nabla \hat{\boldsymbol{v}}+\nabla \hat{\boldsymbol{v}}^{\mathrm{T}}\right)
\end{aligned}
$$

（46）式を運動方程式（38）に代入・変形すると, 次式が 得られる。

$\chi_{R a} \cdot \nabla^{2} \boldsymbol{v}+\left[\nabla \cdot \chi_{R a}\right] \cdot \nabla \boldsymbol{v}+\nabla \boldsymbol{v}: \nabla \chi_{R a}-\rho \hat{\boldsymbol{v}} \cdot \nabla \boldsymbol{v}-\nabla p-\nabla \cdot \boldsymbol{c}+\rho \boldsymbol{g}=0$

この式より, 特性テンソル $\chi_{R a}$ は, 速度の 2 次微分項の係 数であり，このテンソルの成分で運動方程式の型特性が判 別できる、楕円型特性を保持するためには, 次式の判別式 が負の值を満足する必要がある。

$$
D \equiv\left(\chi^{13}\right)^{2}-\chi^{11} \chi^{33}<0
$$

$\chi^{i j}$ は特性テンソル $\chi_{R a}$ の成分であり, 次式で示される.

$$
\begin{aligned}
& \chi^{11} \equiv \lambda \hat{\boldsymbol{E}}^{11}+\left(\eta_{0}+\eta_{a}\right) \\
& \chi^{13} \equiv \lambda \hat{\boldsymbol{E}}^{13} \\
& \chi^{33} \equiv \lambda \hat{\boldsymbol{E}}^{33}+\left(\eta_{0}+\eta_{a}\right)
\end{aligned}
$$

各節点值を用いると判別式（49）を評価することができ， 付加粘性 $\eta_{a}$ を増すと， $D$ に対して負の值が加わり，楕円 型特性が強まることがわかる.

仮に $D>0$ となる領域が存在すると，運動方程式は双曲 型特性を示すようになり，楕円型として設定した境界条件 と整合が取れず，運動方程式が解けなくなることが考えら れる. そこで, Iwata et al. ${ }^{35)}$ は, 判別式に注意しながら 適切な付加粘性を導入することにより, 収束性が改善され ることを示した。

\section{3. おわ り に}

粘弾性流動解析では，様々な定式化手法があることを紹 介した。有限要素法の市販ソフトの中には, オプションの 選択だけで，これらの手法の幾つかを利用することが可能 
である。しかしながら，定式化手法には，長所と短所がそ れぞれ存在する。その手法の特徴を十分に理解することが 大切である。読者がより難しい計算にチャレンジするとき に，ここから得られた知見がその助けとなることができれ ば幸いである。

\section{References}

1 ) Huepner, K. H.: “The Finite Element Method for Engineers," John Wiley and Sons, New York, Chapter 1 (1975)

2 ) Courant, R.: Bull. Am. Math. Soc., 49 (1943)

3 ) Turner, M. J.; Clough, R. W.; Martin, H. C.; Topp, L. J.: J. Aeronaut. Sci., 23(9) (1956)

4 ) Clough, R. W.: "The Finite Element Method in Plane Stress Analysis," Proceedings of 2nd ASCE Conference on Electronic Computation, Pittsburgh Pa., Sept. 8 and 9, (1960)

5 ) Chen, Z:: "Finite Element Methods and Their Applications," Springer, p.4, Germany (2005)

6 ) Zienkievicz, O.C.; Taylor, R.L.: "The Finite Element Method," Vol.3 Fluid Dynamics, 5th Ed., Butterworth-Heinemann, Oxford, Chapter 2 (2000)

7 ) Mitsoulis, E.: Encyclopedia of Fluid Mechanics, Vol.9 (edited by N.P.Cheremisinoff), "Polymer Flow Engineering” , Gulf Publishing Co., Houston, pp.649-704 (1990)

8 ) Luo, X.-L.; Tanner, R. I.: J. Non-Newtonian Fluid Mech., 31, 143$162(1989)$

9 ) Iwata, S.; Aragaki, T.; Mori, H.; Shin, Y.; Ishikawa, S.; Iwabuchi, K.: Seikei-Kakou, 10(10), 824-831 (1998)

10) Kawahara, M.; Takeuchi, N.: Comput. Fluids, 5, 33-45 (1977)

11) Crochet, M. J.; Keunings, R.: J. Non-Newtonian Fluid Mech., 10, 8594 (1982)

12) Van Schaftingen, J. J.; Crochet, M. J.: J. Non-Newtonian Fluid Mech., 4, 1065-1081 (1984)

13) Nakamura, K.: “Hi-Newton Ryutai Rikigaku," Koronasha, Tokyo, Chapter 6 (1990)

14) Tam, K. C.; Tiu, C.: J. Non-Newtonian Fluid Mech., 31, 163-177 (1989)

15) Marchal, J. M.; Crochet, M. J.: J. Non-Newtonian Fluid Mech., 26, 77-114 (1987)

16) Luo, X.-L.; Tanner, R. I.: J. Non-Newtonian Fluid Mech., 21, 179199 (1986)

17) Tanoue, S.; Koga, J.; Kajiwara, T.; Iemoto, Y.; Funatsu.; K.: Seikei Kakou, 9, 817-824 (1997)

18) Tomita, Y.: “Reoroji," Koronasha, Tokyo, Chapter 8 (1975)

19) Baaijens, F. P. T.; Selen, S. H. A. ; Baaijens, H. P. W.; Peters, G. W. M.; Meijer, H. E. H.: J. Non-Newtonian Fluid Mech., 68, 173-203 (1997)
20) Otsuki, Y.; Kajiwara, T.; Funatsu, K.: Polym. Eng. Sci., 39, 19691981 (1999)

21) Rajagopalan, D.; Armstrong, R. C.; Brown, R. A.: J. Non-Newtonian Fluid Mech., 36, 159-192 (1990)

22) Brown, R. A.; Szady, M. J.; Northey, P. J.; Armstrong, R. C.: Theoret. Comput. Fluid Dynamics, 5, 77-106 (1993)

23) Szady, M. J.; Salamon, T. R.; Liu, A. W.; Bornside, D. E.; Armstrong, R. C.; Brown, R. A.: J. Non-Newtonian Fluid Mech., 59, 215243(1995)

24) Liu, A.W.; Bornside, D. E.; Armstrong, R. C.; Brown, R. A.: J. Non-Newtonian Fluid Mech., 77, 153-190 (1998)

25) Sun, J.; Smith, M. D.; Armstrong, R. C.; Brown, R. A.: J. NonNewtonian Fluid Mech., 86, 281-307 (1999)

26) Sunwoo, K. B.; Park, S. J.; Lee, S. J.; Ahn, K. H.; Lee, S. J.: J. NonNewtonian Fluid Mech., 99, 125-144 (2001)

27) Osswald, T.; Menges, H.; under the editorship of Takeda, K.: "Materials Science of Polymers for Engineers," Sigma-shuppan, Tokyo, Chapter 4 (1997)

28) Polyflow Users Guide, v12.1, Ansys Inc., Chapter 11 (2010)

29) Tseng, H. C.; Lin, G. G.: Int. J. Numer. Methods. Fluids, 10, 637-649 (1990)

30) Upadhyay, R. K.; Isayev, A. I.: Rheol. Acta, 25, 80-94 (1986)

31) Schmidt, F. M.; Agassant, J. F.; Bellet, M.; Desoutter, L.: J. NonNewtonian Fluid Mech., 64, 19-42 (1996)

32) Sun, J.; Phan-Thien, N.; Tanner, R. I.: J. Non-Newtonian Fluid Mech., 65, 75-91 (1996)

33) Iwata, S.; Aragaki,T.; Mori, H.; Ishikawa, S.; Shin, Y.: SeikeiKakou, 12(2), 115-121 (2000)

34) Iwata, S.; Aragaki,T.; Mori, H.; Ishikawa, S.; Waki, H.: SeikeiKakou, 12(8), 523-529 (2000)

35) Iwata, S.; Aragaki,T.; Mori, H.; Hattori, M.; Waki, H.: J. Chem. Eng. Japan, 35(7), pp.660-669 (2002)

\section{日本語表記参考文献}

9 ) 岩田修一, 新垣勉, 森秀樹, 秦裕作, 石川敏志, 岩渕欽也：成 形加工, 10(10), 824-831 (1998)

13）中村喜代治：非ニュートン流体力学, コロナ社, 東京, 6 章 (1990)

17）田上秀一, 古閑二郎, 梶原稔尚, 家元良幸, 船津和守：成形加 工, 9, 817-824 (1997)

18）富田幸雄：レオロジー, コロナ社, 東京, 8 章（1975）

27） Osswald, T.; Menges, H.: 旭化成工業（株）樹脂開発・技術セン 夕ー 若手技術研究会訳, 武田邦彦監修: エンジニアのための プラスチック材料工学, シグマ出版, 東京, 4 章 (1997)

33）岩田修一, 新垣勉, 森秀樹, 石川敏志, 秦裕作 : 成形加工,12 (2) , 115-121 (2000)

34）岩田修一, 新坦勉, 森秀樹, 石川敏志, 和気光 : 成形加工,12 (8) , 523-529 (2000) 